\title{
UNA VIDA QUE JUEGA CON LA MUERTE O SOBRE LOS TOPOS DE FÉLIX BRUZZONE
}

\author{
Victoria Daona \\ Centro de Investigaciones Sociales \\ Instituto de Desarrollo Económico y Social \\ Consejo Nacional de Investigaciones Científicas y técnicas \\ vicdaona@gmail.com
}

Resumen: En este artículo propongo analizar Los Topos (2008) de Félix Bruzzone tomando como punto de partida los ejes que comparte con las otras narrativas del género de los/as hijos, para luego poder pensar su divergencia. $\mathrm{Si}$ bien sus libros $\mathrm{y}$ performances están atravesados por la ausencia de los padres y por la incertidumbre que sus múltiples narradores -todos hijos de desaparecidos- tienen ante los hechos vinculados a esas desapariciones; la historia familiar se presenta siempre fragmentada y en un segundo plano, por lo que la acción de reconstrucción de esa genealogía resulta incompleta. Lo que diferencia a su producción de otras narrativas de hijos/as, es que sus narradores no buscan saber todo sobre sus padres. Bruzzone crea una poética en torno a esa incertidumbre. Las preguntas que el texto provoca tienen que ver con la constitución de las identidades en procesos personales y colectivos que están atravesados por la violencia, no sólo la del Terrorismo de Estado, sino también aquella que asume formas más actuales, vinculadas principalmente con los cautiverios, la trata de personas y los travesticidios.

Palabras clave: Hijo de desaparecidos, Narrativas, Identidad, Subjetividad, Devenir.

\begin{abstract}
I propose to analyze Los Topos (2008) by Félix Bruzzone, looking at the similiarities that his narratives shares with the other narratives of children of disappeared, and also, thinking about their divergence. Although his books and performances are crossed by the absence of the parents and by the uncertainty that his multiple narrators all children of disappeared persons have about all those disappearances; the family novel is always fragmented and, in the background, so the reconstruction of this genealogy is incomplete. What differentiates his production from all those other narratives, is the fact that his narrators are not specialists of their parents. Bruzzone creates a poetic about uncertainty. His narratives inquire about the constitution of identities in personal and collective processes that are crossed by violence, not only the violence of State Terrorism, but also that which assumes more current forms, linked to captivity, kidnapping of persons and transvestite's death.
\end{abstract}

Keywords: Dissapeared'son, Narratives, Indentity, Subjectivity, Becoming. 

El extenso corpus de novelas de hijos/as de desaparecidos/as en Argentina, y las similitudes que comparten entre sí, nos habilitan a hablar de un género literario que representa el momento más acabado de la narrativa argentina en torno al pasado reciente. Estas producciones logran dar cuenta de experiencias de vida que se constituyen y están atravesadas por la violencia y la persecución política, el exilio o la desaparición de los padres y las madres y por la lucha de los organismos de Derechos Humanos, en donde la fundación de H.I.J.O.S. resulta clave para estas narrativas. A su vez, los/as protagonistas buscan contar la historia de la propia vida más allá o más acá de esas experiencias límites e incluso proponen una transmisión que interpele a las generaciones más jóvenes (Basile 2019; Daona, 2017).

En este artículo propongo analizar Los Topos (2008) de Félix Bruzzone tomando como punto de partida los ejes que comparte con las otras narrativas del género de los/as hijos, para luego poder pensar su divergencia. Puesto que si bien sus libros y performances están atravesados por la ausencia de los padres y por la incertidumbre que sus múltiples narradores todos hijos de desaparecidos- tienen ante los hechos vinculados a esas desapariciones; la historia familiar se presenta siempre fragmentada y en un segundo plano, por lo que la acción de reconstrucción de esa genealogía resulta siempre incompleta ${ }^{1}$. Lo que diferencia a su producción en relación a

\footnotetext{
1 Podríamos decir que Los Topos (2008) y 76 (2008) de Félix Bruzzone, junto a La casa de los conejos (2008) de Laura Alcoba, constituyen el inicio del género de los hijos/as en la literatura, en tanto a partir de sus publicaciones podemos identificar todos los otros libros que vinieron después. En este sentido, se puede pensar como precedente del
} 
otras obras del género es que sus narradores no buscan saber todo sobre sus padres", sino que Bruzzone crea una poética en torno a esa incertidumbre. La condición de ser hijo de desaparecidos es algo con lo que los narradores conviven desde el inicio de las ficciones y sobre lo que no quieren detenerse o prefieren indagar poco.

Teresa Basile (2019) analiza la obra de Bruzzone desde la idea de una orfandad suspendida que se caracteriza por una primera fase marcada por la espera y una segunda, atravesada por la búsqueda. El concepto de búsqueda es clave para entender esta poética, en tanto sus narradores siempre están en fuga. No se trata de una búsqueda por los orígenes -la novela familiar- sino una búsqueda que implica, principalmente, movimiento. Lo que nos lleva a pensar el concepto de "devenir" que plantean Gabriel Giorgi y Fermín Rodríguez en la introducción al libro Ensayos sobre biopolitica. Excesos de vida (2007) en donde señalan que la biopolitica no propone estudiar la vida de alguien en su singularidad, sino ese flujo de pura vida despojada de su soporte humano (2007, p. 16).

Los Topos comienza así:

Mi abuela Lela siempre dijo que mamá, durante el cautiverio en la ESMA, había tenido otro hijo. Varias veces la oía discutir del tema con mi abuelo. Ellos se iban al fondo, al zapallar, y hablaban de todo lo que yo no tenía que saber. Pero a veces me escondía entre las hojas de los zapallos, que para mí eran un lugar de juego, yo soldado,

género el libro Atravesando la noche. 79 sueños y testimonios acerca del genocidio de Andrea Suárez Córica (1996), que analiza Miguel Dalmaroni en La palabra justa (2004). 
refugiado vietnamita, yarará, zapallo, las fuerzas de las plantas crecían a mi alrededor, explosión lenta y duradera, y cuando mis abuelos llegaban para hablar los escuchaba (Bruzzone, 2014, p. 11).

El párrafo que abre la novela condensa todos los tópicos, o al menos los principales, sobre los que se organiza el género: mamá, secuestro, cautiverio, Esma, otro hijo, los abuelos, los juegos de infancia, el zapallar, la fuerza de las plantas, explosión lenta y duradera, lo que no tenía que saber, pero escuchaba. La lista expone -en un orden caprichoso- los elementos que en la construcción de estas narrativas pueden variar, pero no pueden faltar y que están íntimamente ligados al proceso de conformación de las subjetividades e identidades frente a experiencias de filiación traumáticas en la infancia.

Lo primero que conocemos del narrador es que su madre estuvo en cautiverio en la Esma y lo sabemos gracias a la abuela Lela, que no sólo se encarga de las lógicas del cuidado, sino también de las lógicas de la transmisión. Pero, además, es la abuela la que sabe que su hija tuvo otro hijo en cautiverio y es por esta convicción que decide vender su casa en Moreno y comprar un departamento que tenga vista a la ESMA, con la ilusión de que esa cercanía también los acerque a la verdad. Una vez instalados allí, la abuela mirará todos los días el edificio por la ventana, sin embargo muy pocas veces se acercará al lugar y nunca a algún organismo de DD.HH que pueda orientarla en la búsqueda.

El cautiverio configurará en un mismo espacio -la ESMA- la muerte de la madre y el nacimiento del hermano, dando lugar a 
una conflictiva fusión entre la vida y la muerte que tensionará toda la trama de la novela y que es la que nos habilita a hablar de una poética del devenir. Como señalan Giorgi y Fernández: "entre el nacimiento y la muerte, se trata en ambos casos de una vida impersonal, pre-personal, a-subjetiva, despojada de atributos, no plegada todavía en el adentro y el afuera de un sujeto y un objeto; una fuerza que emerge como singularidad indefinida según una indefinición que se refiere a modos de lo no-formado, a lo que más que cerrarse en una «forma» total, afirma su apertura al devenir, a lo virtual.” (2017, p. 16). Cómo veremos, será esa fuerza indefinida la que traccionará el derrotero del narrador hacía una apertura del devenir en la que él irá perdiendo toda singularidad.

La historia de vida del narrador aparecerá siempre fragmentada, por retazos, como si los lectores estuviéramos también en el zapallar escuchando hablar a los abuelos por lo bajo. Su biografía está atravesada por la desaparición de su madre, por la incertidumbre en torno al paradero de su hermano, y por la traición de su padre y la incógnita sobre su destino -sabemos que fue el padre quien entregó a su madre y luego nadie volvió a verlo, por lo que no se sabe si es un desaparecido o no-. Y si bien el narrador nunca manifiesta sentimientos que permitan al lector entender qué le provoca este origen, a lo largo de la novela podemos ver de qué manera inciden en su historia de vida y en su presente, ese pasado y ese linaje marcados por el terrorismo de estado en toda su complejidad.

Será Romina -su novia- el primer personaje de la novela en acercarse a un organismo de DD.HH -en este caso H.I.J.O.S.- 
y comenzar a militar allí como gesto de amor y compromiso con el narrador, aunque ella sea completamente ajena a esa historia de desaparecidos. Romina le insistirá a él para que también se involucre en la agrupación argumentando que esa militancia lo salvaría porque la gente allí adentro es muy valiosa. El narrador se niega a ser parte de la organización porque aunque no tiene nada en contra de los hijos que la conforman, no se siente involucrado en esa militancia ni considera que debe pertenecer a ella sólo por compartir ese origen común con todos los demás miembros. El narrador cuestiona la legitimidad sanguínea que reclaman los organismos de DD.HH, y ese gesto divergente se irá profundizando a lo largo de la trama a medida que vaya rompiendo todos los vínculos afectivos y materiales que le recuerdan su condición de hijo de desaparecido.

El primer alejamiento será el de Romina, que se termina de concretar con la decisión de que ella aborte el bebé que está esperando. El embarazo sucede en algún momento de la década de 1990, en la época en que estaban por salir las indemnizaciones del gobierno. "Lo que significaba recibir esa plata, y la necesidad de volver a verme con Romina por lo del embarazo, detonaron algunas cosas" (Bruzzone, 2014, p. 25), dice el narrador, refiriéndose a la frecuencia con la que comienza a visitar a las travestís que se ubicaban en la zona de Godoy Cruz y Niceto Vega en el barrio de Palermo en la Ciudad de Buenos Aires. Ese contacto que al principio comienza como un juego, deja de serlo cuando el narrador conoce a Maira, una travesti a la que lleva a pasear en su auto y con la que siente que puede hablar de su historia. 
Al momento de cobrar la indemnización, el narrador gastará la plata en el aborto, en Maira y en llevar a su abuela de viaje. En Brasil, Lela ve a un joven que para ella es el nieto que estaba buscando, pero no se quedan para encontrarlo puesto que el narrador le dice que mejor regresen a Buenos Aires y que luego volverían para concretar la búsqueda. Sin embargo nunca regresan y su abuela muere tiempo después. Allí se produce el segundo y el tercer alejamiento con los cuales no sólo pierde el último vínculo familiar que le quedaba y la posibilidad de dejar descendencia, sino que también se enamora de Maira, quien lo abandona luego de saber que él desea establecer una relación con ella. La tensión vida/muerte va convirtiéndose en pulsión de muerte: muerte de Lela, aborto del bebé, abandono de Maira.

Ante estas circunstancias vende el departamento que quedaba cerca de la ESMA y vuelva a la vieja casa de Moreno, la ocupa y utiliza el dinero de la venta para repararla. Esto lo hace olvidarse por un tiempo de Maira, de Romina y de la historia de su hermano nacido en cautiverio. Sin embargo, cuando la obra ya está encaminada, el narrador decide recuperar a Maira, pero no la encuentra.

"Mientras buscaba a Maira -dirá- además, empecé a sentir la necesidad de confirmar u olvidar para siempre la versión de Lela sobre mi supuesto hermano nacido en cautiverio, como si las dos búsquedas tuvieran algo en común, como si fueran parte de una misma cosa o como si fueran, en realidad, lo mismo" (Bruzzone, 2014, p. 41). 
Frente a esa comprobación, el narrador también comenzará a buscar a su hermano en distintos organismos de DD-HH y en esa búsqueda nuevamente pareciera olvidarse de Maira hasta que una mañana se la cruza saliendo de una tintorería en Moreno y comienza a seguirla sin que ella se dé cuenta. La persecución se prolongará durante varios días en los cuáles el narrador irá tejiendo diferentes hipótesis de quién es Maira, puesto que no sólo es una travesti que ejerce la prostitución, sino que además el narrador comprueba que ella tiene vinculaciones con la policía. Uno de esos días la sigue hasta la Plaza del Congreso donde ella se reúne con un grupo de militantes de H.I.J.O.S. Las sospechas sobre Maira crecen hasta que llega a la conclusión de que es una entregadora que trabaja con la policía.

Decide entonces denunciarla, pero cuando llega a H.I.J.O.S. y cuenta su historia, descubre que Maira también es un hijo de desaparecidos que no sólo se dedica a matar torturadores sino que además busca a su hermana nacida en cautiverio y es por eso que ella se viste de mujer. La develación de la identidad y los motivos por los que Maira mantenía contactos con la policía perturban al narrador a la vez que funcionan como un espejo invertido de su propia historia y de la imposibilidad que él tiene para concretar ciertas acciones. Puesto que, si bien dice que le gustaría matar policías y buscar a su hermano, es algo que nunca concreta y que Maira pone en práctica.

Frente a estas comprobaciones, el narrador decide buscarla y proponerle iniciar una nueva vida juntos en Bariloche. Y aunque sospecha que ella puede ser el hermano que él está buscando y sabe que amarla en esas condiciones resulta 
incestuoso, no le importa. El problema es que cuando llega a la casa de Maira descubre que alguien ha estado allí, revolvió todo y se la llevó. Con Maira se produce el cuarto y último alejamiento del narrador con esa historia pasada, pero además su secuestro actualiza el tópico de la desaparición forzada de personas, lo que habilita al narrador establecer una genealogía de la desaparición y la violencia que se inicia en dictadura, y se continúa en democracia.

Ya imaginaba al tipo de las manchas en los ojos hablando sobre los neodesaparecidos o los postdesaparecidos. En realidad, sobre los postpostdesaparecidos, es decir, los desaparecidos que venían después de los que habían desaparecido durante la dictadura y después de los desaparecidos sociales que vinieron más adelante. Porque ahora parecía llegar el turno de que desaparecieran también los que, como Maira, en su búsqueda de justicia, se pasaban un poco del límite (Bruzzone, 2014, p. 80).

La frase, "pasarse un poco del límite", resulta elocuente en tanto Maira no sólo traspasa el límite de la justicia, y busca hacerla por mano propia en una época de suspensión total de los juicios sobre crímenes de lesa humanidad como fue la década de 1990, sino que además traspasa los límites binarios del género al travestirse de mujer en un intento por encontrar a su hermana nacida en cautiverio. Los límites que traspasa Maira en la novela nos llevan nuevamente a pensar esa tensión entre vida y muerte a partir de la interrogación por el paradero 
de Maira y esa suspensión de su vida en simultáneo a la incerteza de su muerte.

Por otra parte, mientras tiene lugar la persecución a Maira, el narrador comienza a dejar a los albañiles solos en la casa con un juego de llaves para que se manejen sin necesidad de que él esté presente. El problema es que, al regresar un día, se da con que los albañiles descubrieron que él no es el verdadero dueño y deciden echarlo de allí. Al quedarse sin casa, el narrador sale a dar vueltas con su auto, que luego también se lo robarán y pierde con él no sólo su último bien material, sino también todos sus documentos. A partir de ese momento se queda sin elementos materiales que le permitan conectarse con su identidad, su historia personal y su pasado. La identidad tambaleante (Pollak, 2006), que oscila entre la destrucción y la recomposición, se materializa en la pérdida total de vínculos y documentos que sustenten esa identidad. El narrador se convierte en un paria, sin familia, sin documentos, sin casa y sin dinero. Hasta que, por alguna información que tiene sobre el posible paradero de Maira decide irse a Bariloche.

Allí se emplea en la construcción y su jefe será El Alemán, un hombre de quien se sospecha que fue torturador durante la dictadura militar y que mantiene una doble vida, puesto que de día es un esposo y padre ejemplar y por la noche se dedica a levantar travestis en su camioneta para golpearlas y luego asesinarlas. El narrador comienza a sospechar que El Alemán es quien secuestró y desapareció a Maira a la vez que confunde esa figura del torturador con la de su padre. Urde entonces un plan para vengar a Maira que consiste en convertirse en travesti, seducir a su jefe y luego asesinarlo. 
Sin embargo, ese plan se ve frustrado una vez que El Alemán aparece, puesto que comienzan a tener una relación que en un principio será sólo sexual y luego se transformará en una relación amorosa y sadomasoquista en la que aquel secuestra al narrador y lo mantiene como a una amante en una cabaña en la montaña. Al igual que con su historia familiar, frente a esta situación de encierro forzoso el narrador no manifiesta grandes preocupaciones, sino que se va acrecentando el amor que siente por su secuestrador. Al mismo tiempo que no considera que su vida haya cambiado desde que comienza la narración hasta ahora.

Los cambios - dice el narrador-, desde mi llegada a la casa revuelta de Maira, no habían sido tantos. No en lo profundo que es donde debe trabajar en verdad el destino. En la superficie sí. Y ni que hablar de los cambios que vendrían en adelante. Pero en lo profundo las cosas siempre habían conservado la misma dirección, como si mi vida hubiera sido una serie de accidentes que apenas daban una idea de lo que realmente sucedía (Bruzzone, 2014, p. 107).

La idea de entender la propia vida como una serie de accidentes nos sitúa nuevamente ante la idea del devenir, en donde la vida individual se despoja de una corporalidad particular y puede asumir múltiples formas. "La vida -señalan Giorgi y Rodríguez- es eso que deviene, eso que «pasa» y que moviliza los cuerpos, los saca de sus formas y de sus figuras y los lleva más allá, a su mutación y su mezcla, en un proceso que es siempre singular en tanto que produce una diferencia 
positiva." (2007, p. 25). Pero además, la idea de entender su vida como una serie de accidentes resulta productiva para pensar cómo se van tramando los acontecimientos de esta historia puesto que el narrador está constantemente iniciando búsquedas que nunca concluyen, al mismo tiempo que esas búsquedas siempre están encadenadas las unas a las otras, por lo que nunca termina la acción de buscar.

De esa manera accidental es que el narrador se entera que El Alemán conoció a una tal Maira que vivía en Liniers que le decía que él era su papá y le inventaba una historia de doble agente en la que él había entregado a su mamá. Es a partir de esa declaración que él confirma las sospechas no sólo de que aquel fue quien desapareció a Maira, sino de que ella es el hermano que estuvo buscando y el Alemán su padre. Y aunque esas suposiciones no pasan de ser elucubraciones, él comienza a soñar con la posibilidad de un encuentro entre los tres y la conformación de una nueva familia que reúna por fin los ideales por los que lucharon no sólo su madre, sino también su hermana. "Lo que Maira quería, lo que quería mamá, y papá a su manera, mundo nuevo, nuevo mundo, hombre nuevo, hombres felices" (Bruzzone, 2014, p. 185).

La ilusión de esa nueva familia proyectada en un futuro utópico, se asemeja al ideal de un nuevo mundo por el que miles de hombres y mujeres tomaron las armas, disciplinaron sus cuerpos y ofrecieron -literalmente- sus vidas en nombre de la revolución. (Rosano, 2014). En Los Topos el narrador siente por su captor un enamoramiento que es por el cual soporta las vejaciones padecidas, a la vez que es ese enamoramiento el que lo habilita a generar estrategias de sobrevivencia, ligadas al 
cuidado amoroso del Alemán. El narrador cocinará para su captor, lo escuchará paciente y comprensivamente, satisfacerá sus deseos sexuales e incluso se someterá a una operación de senos por imposición del Alemán. La feminización del personaje será total y sin embargo, para él, nada habrá cambiado.

Hacía el final de la novela, no se resuelve la situación de encierro y si bien podemos suponer que el narrador terminará asesinado como todas las demás travestis, es algo que nunca sabremos y que, desde la perspectiva del devenir, pierde sentido, en tanto el eje de la trama está puesto en esa mutación en la que fluye sin perderse, el flujo de una vida. "La vida dicen Giorgi y Rodríguez- es un estado de devenir o diferenciación constante, de cambio y metamorfosis, el estado libre y salvaje de la diferencia pura" (2007, p. 22).

La novela de Bruzzone introduce una temática nueva en torno a la narrativa de la violencia política que es la del travestismo y las teorías "queers" para pensar la conformación de nuevas identidades (Saxe, 2014) ${ }^{2}$. Como en un círculo imperfecto, el narrador de Los Topos (2008) termina igual que

\footnotetext{
2 A propósito de lo "queer" dice Amy Kaminsky en "Hacia un verbo queer" (2008): "En nuestro campo, por razones de compresión histórica, lo queer se asimila a lo lésbico-gay. Sin embargo, la teoría queer desarrollada con más amplitud y más tiempo en las academias norteamericanas mantiene que lo queer es precisamente el concepto que pone en tela de juicio los binarismos ejemplificados por la oposición lesbiana-gay. Si bien el término queer se destaca por su labilidad -igual que "homosexual", "gay" o "lesbiana", queer puede referirse a una identidad autorial o a una temática; también puede nombrar un proceso, un modo o una actitud-, "Lesbiana' y 'gay" son identidades que parten de un paradigma moderno, basado en el concepto de un sujeto estable, mientras que la perspectiva más bien posmoderna posibilitada por el vocablo "queer" rechaza tanto la estabilidad del sujeto como una teoría arraigada en una concepción esencialista de la identidad" (Kaminsky, 2008, p. 882).
} 
como desapareció su madre, secuestrada, torturada, abusada y desaparecida. Su condición de hijo de desaparecido resulta central para entender el derrotero que realiza el narrador, aunque no resulta suficiente para abordarlo. Puesto que sus búsquedas no tienen que ver con la necesidad de conocer quiénes fueron sus padres, denunciar los crímenes cometidos por el terrorismo de estado o iniciar una nueva militancia; sino que tienen que ver con preguntas más complejas en torno a la conformación de la identidad, de la sexualidad y de la familia más allá de los marcos heteronormativos y de los parentescos de sangre, e incluso más allá de la singularidad de una historia.

Los Topos (2008) forma parte de esas narraciones que Nicolás Prividera llamó "mutantes", que "explicitan y ponen en el centro de la escena la esencial inadecuación" de los hijos" de desaparecidos y la necesidad de buscar respuestas a esa historia en el presente y en el futuro, más que en el pasado. "Esa mutación -sostiene Prividera- produce obras abiertas, imperfectas, y de múltiples caras (aunque no escapen a un involuntario "espíritu de época") cuyo aire familiar es su ofendido pero nunca humillado desamparo, que sabe que esa intemperie puede ser también una condición de posibilidad, para construir desde esa mirada un inquebrantable mundo propio" (Prividera, 2009). Entre el espíritu de época -marcado por el surgimiento de H.I.J.O.S y la suspensión de la justicia- y el mundo propio -como posibilidad de construir un relato diferente al de los organismos aunque no completamente rupturista-, la condición "mutante" de ciertas obras hace, para Prividera. "de la diferencia una forma y una formulación" (Prividera, 2009). 
En el caso de la novela de Bruzzone, la inadecuación del personaje se va manifestando en esas múltiples transformaciones que va viviendo sin cuestionarlas, hasta modificar su cuerpo por completo al implantarse senos. La figura de la travesti manifiesta de modo evidente esa inadecuación en tanto representa aquello que traspasa la heteronormatividad y necesita de nuevos marcos para ser pensado. Pero, además, en esta novela no hay transmisión generacional, sino que se corta la posibilidad de transmitir ese pasado. Primero porque el narrador casi no habla de su historia personal, segundo porque decide que su novia aborte la única posibilidad de descendencia que tiene y tercero porque al final no se vislumbra ninguna salida a esa situación de encierro, ni la posibilidad de que esa historia pasada tenga sentido para sus captores o para alguien en el futuro. Perdidos los marcos de contención, cuidado y anclaje identitario, lo que queda es la voz del narrador, el flujo de su conciencia o -como diría Deleuze- "un momento que no es más que el de una vida que juega con la muerte" (Deleuze, 2007, p. 38).

\section{Coda}

Este artículo se escribe en simultáneo a la publicación de Campo de Mayo (2019) la última novela de Félix Bruzzone y la segunda, después de Los Topos (2008), en la que el escritor pone en escena a un hijo de desaparecidos. Las diferencias entre una novela y otra son muchísimas, pero las primeras que se observan son el cambio en la voz narradora -que pasa de 
una primera a una tercera persona- y en el protagonista -que pasa de ser anónimo a llamarse Fleje-. Dejo para un futuro el análisis minucioso de esta nueva novela en la que la madre, el hijo y ¿una ironía trágica? del destino podrían leerse como una reescritura de Edipo Rey.

Lo que me interesa enfatizar es que en Campo de Mayo (Bruzzone, 2019) la búsqueda sigue siendo la matriz que desencadena la acción, y el movimiento, el eje sobre el que se sostiene la trama. Fleje -el protagonista- corre descalzo por la guarnición militar que da nombre a la novela, en un intento por pisar la misma tierra que pisó su madre cuando estuvo secuestrada en ese lugar. Fleje corre sin descanso y en esa acción busca, encuentra, abandona y vuelve a empezar, como si lo único importante fuera repetir esa acción mil veces y dejar fluir el devenir.

Léase esta coda como un llamado de atención para futuros/as lectores/as o como una adenda urgente para los escritos que vendrán.

\section{Referencias Bibliográficas}

Basile, T. (2019). Infancias. La narrativa argentina de HIJOS. Córdoba. EDUVIM

Bruzzone, F. (2014). Los Topos. Buenos Aires. Mondadori (2019). Campo de Mayo. Buenos Aires. Mondadori 
Dalmaroni, M. (2004). La palabra justa. Literatura, crítica y memoria en la Argentina. 1960-2002. Santiago de Chile: RIL- Melusina Editorial.

(2017). "Las voces de los/as hijos/as de desaparecidos/as en Argentina: un género". El taco en la brea, 6, 37-55.

(2018). "Voces y poéticas de la memoria: un corpus de novelas argentinas contemporáneas". Revista Chilena de Literatura, 97, 105-126.

Deleuze, G. (2007). "La inmanencia: una vida...”. G. Giorgi y F. Rodríguez. Ensayos sobre biopolítica. Excesos de vida. Buenos Aires: Paidós, pp. 41-58.

Giorgi, G. y Rodríguez, F. (2007). Ensayos sobre biopolítica. Excesos de vida. Buenos Aires: Paidós.

Jelin, E. (2002). Los trabajos de la memoria. Buenos Aires: Siglo XXI Editores.

Kaminsky, A. (2008) "Hacia un verbo queer". Revista Iberoamericana, vol. LXXIV, núm. 225, 879-895.

Kaufman, S. G. (2006). "Lo legado y lo propio. Lazos familiares y transmisión de memorias". Jelin, E. Kaufman, S. (comps.). Subjetividades y figuras de la memoria. Buenos Aires: Siglo XXI Editores, pp. 47-71.

Nofal, R. (2015) "Configuraciones metafóricas en la narrativa argentina sobre memorias de dictadura”. Revista Kamchatka, $6,835-851$.

Pollak, M. (2006). Memoria, Olvido, Silencio. La producción social de identidades frente a situaciones límite. La Plata: Ediciones Al Margen.

Prividera, N. (2009) "Plan de evasión. Presentación de Los Topos de Félix Bruzzone". Recuperado de http://haciaelbicentenario.blogspot.com.ar/2009/05/plande-evasion.html. 
Rosano, S. (2014) "Los cuerpos de la militancia”. M. Moraña e I. Sánchez Prado (eds). Heridas abiertas: Biopolítica y Representación en América Latina. Barcelona: Iberoamericano Editorial Vervuert.

Saxe, F. (2014) "Dictaduras, narrativa y sexualidad disidente: un enfoque comparatístico de la literatura de la memoria queer" Cuadernos del Sur-Letras, vol. 2012, 265 - 276 